\title{
PENGGUNAAN MULTIMEDIA PEMBELAJARAN INTERAKTIF DENGAN I-SPRING PRESENTER UNTUK MENINGKATKAN MOTIVASI DAN HASIL BELAJAR PENDIDIKAN KEWARGANEGARAAN
}

\author{
${ }^{1)}$ Herlin Rusyani, ${ }^{2}$ Dody Hermana, ${ }^{3)}$ Nizar Alam Hamdani \\ ${ }^{1}$ Dosen Program Studi D3 Kebidanan STIKES Karsa Husada Kabupaten Garut. \\ Email: herlin1506@gmail.com \\ ${ }^{2}$ Dosen Program Pascasarjana Teknologi Pendidikan STKIP Garut \\ Email: Doddy@yahoo.com \\ ${ }^{3}$ Dosen Program Pascasarjana Teknologi Pendidikan STKIP Garut \\ Email: nizar_hamdani@yahoo.com
}

\begin{abstract}
The research is to find out the effectiveness of using interactive learning multimedia with ISPRING PRESENTER to improve motivation and civics education learning outcome in STIkes Karsa Husada Garut.The taken population is nursing students, Diploma III Grade I, STIkes Karsa Husada Garut. The specimen are 1 B grade as control class with 38 students and $1 C$ grade as experiment class with 38 students. The research methodology used in this research is experiment research method with quantitative approach. The used experiment method form is by Quasi Experimental design with Non equivalent Control Group Design form. Data collection instrument for learning motivation uses scale with five choice answer opinions, while learning outcome is done by test. The research result data are previously done by making normality test. Data analysis uses T test with SPSS (Statistical Product and Service Solution) software version 17 and MS.excel 2010.The obtained research results are: 1. Motivation before using learning multimedia is low-value, however by interactive learning multimedia, it is high-value, so there is learning motivation improvement. 2. Learning outcome of experiment group is high, while control group is fair. Those show that students' learning outcome improvement using interactive learning multimedia is better than those using conventional learning.
\end{abstract}

Key words: Interactive Learning Multimedia, Motivation, Learning Outcome

\section{A. PENDAHULUAN}

Sejak bergulirnya era reformasi, kebebasan pers semakin terbuka, walaupun dengan kebebasan pers tersebut ada dampak positif dan dampak negatifnya. Salah satu dampak negatifnya karena pers setiap hari banyak menyuguhkan beritaberita mengenai kriminalitas, kekerasan, korupsi, perkelahian antar warga, tawuran pelajar dan sebagainya. Kalau kita lihat seakan rasa nasionalisme rakyat Indonesia semakin memudar, masyarakat Indonesia seolah lebih banyak yang egois dan mementingkan kepentingan pribadinya dibandingkan kepentingan bangsa.

Barangkali dalam hal ini pendidikan kewarganegaraan sebagai pendidikan karakter yang merupakan mata pelajaran yang diwajibkan untuk 
kurikulum di jenjang pendidikan dasar, menengah dan mata kuliah wajib untuk kurikulum Pendidikan Tinggi, sebagaimana yang diamanatkan dalam Pasal 37 Undang-Undang No. 20 Tahun 2003 tentang Sistem Pendidikan Nasional tidak atau kurang berhasil dalam menumbuhkan wawasan dan kesadaran bernegara, sikap serta perilaku yang cinta tanah air.

$$
\text { Padahal melalui Pendidikan }
$$

Kewarganegaraan, warga negara Republik Indonesia diharapkan mampu memahami, menganalisa, dan menjawab masalahmasalah yang dihadapi oleh masyarakat, bangsa dan negaranya secara konsisten dan berkesinambungan dalam cita-cita dan tujuan nasional seperti yang digariskan dalam Pembukaan UUD 1945 (Sumarsono,dkk, 2008:7).

$$
\text { Berdasarkan hal tersebut }
$$

Pendidikan Kewarganegaraan tidak bisa dianggap remeh karena merupakan mata kuliah yang diwajibkan, sehingga upayaupaya untuk memperbaiki proses pembelajaran Pendidikan Kewarganegaraan di Perguruan Tinggi harus terus ditingkatkan.

Sebagai ilmu sosial, tentunya Pendidikan Kewarganegaraan berbeda dengan ilmu-ilmu terapan yang bersifat pasti. Hal ini akan menjadikan mahasiswa terkadang merasa kesulitan atau malas dalam mengikuti proses pembelajaran, sehingga pembelajaran menjadi kurang bermakna. Hal ini ditunjukkan dengan kurang aktifnya mahasiswa dalam berinteraksi dalam proses pembelajaran. Semua ini terjadi dikarenakan motivasi mahasiswa yang relatif rendah. Padahal motivasi merupakan sesuatu yang dibutuhkan untuk melakukan aktivitas.

Karena kurangnya motivasi tersebut, banyak mahasiswa menganggap proses pembelajaran Pendidikan Kewarganegaraan sebagai sesuatu yang membosankan, monoton, kurang menyenangkan, dan berbagai keluhan lainnya. Juga ada persepsi yang telah menjadi milik sejumlah mahasiswa bahwa ilmu-ilmu sosial itu merupakan ilmu yang membosankan karena sajiannya berteletele. Ketika persepsi negatif itu merasuki pikiran mahasiswa, maka minat dan motivasi belajarnya menjadi merosot. Akibatnya hasil belajar menjadi kurang maksimal.

Dengan melihat kurangnya motivasi dan belum optimalnya hasil belajar mahasiswa, maka perlu dicari jalan keluar untuk memecahkan persoalan tersebut. Hal yang harus dilakukan adalah dengan menggunakan metode yang cocok dengan kondisi mahasiswa, agar mahasiswa dapat berfikir kritis, logis dan dapat memecahkan masalah dengan sikap terbuka, kreatif dan inovatif.

Dengan perkembangan ilmu pengetahuan dan teknologi yang semakin pesat, dimana penggunaan teknologi juga sudah merambah dunia pendidikan, kita bisa memanfaatkan teknologi tersebut untuk keberhasilan dalam proses pembelajaran, salah satunya dengan menggunakan multimedia pembelajaran interaktif dengan I-Spring Presenter. Dimana dengan penggunaan multimedia pembelajaran interaktif ini diharapkan akan mendorong motivasi mahasiswa untuk lebih menyukai pembelajaran yang disajikan, sehingga apabila motivasi belajarnya sudah tumbuh, diharapkan akan mendorong prestasi belajar mahasiswa semakin baik dan semakin meningkat.

Adapun yang menjadi permasalahan utama adalah "Bagaimana meningkatkan motivasi dan hasil belajar mahasiswa dalam perkuliahan Pendidikan Kewarganegaraan?" Secara spesifik permasalahan dalam meningkatkan motivasi dan hasil belajar mahasiswa diuraikan sebagai berikut: 
1. Bagaimana meningkatkan motivasi mahasiswa dalam pembelajaran pendidikan Kewarganegaraan.

2. Bagaimana meningkatkan hasil belajar mahasiswa dalam pembelajaran pendidikan Kewarganegaraan.

Untuk menghadapi permasalahan tersebut diatas, diupayakan agar dosen mampu mengorganisir perkuliahan secara inovatif dengan harapan kualitas proses dan produk pembelajaran Pendidikan Kewarganegaraan ini dapat semakin baik dan mendorong ketertarikan mahasiswa terhadap mata kuliah ini.

\section{B. KAJIAN LITERATUR}

\section{Motivasi Belajar}

Menurut Sardiman (2007:75) motivasi dapat diartikan sebagai serangkaian usaha untuk menyediakan kondisi-kondisi tertentu, sehingga seseorang mau dan ingin melakukan sesuatu, dan bila ia tidak suka, maka akan berusaha untuk meniadakan atau mengelak perasaan tidak suka itu. Jadi motivasi itu dapat dirangsang oleh faktor dari luar tetapi motivasi itu adalah tumbuh dalam diri seseorang.

Sementara menurut Uno (2012:23), hakikat motivasi belajar adalah dorongan internal dan eksternal pada siswa-siswa yang sedang belajar untuk mengadakan perubahan tingkah laku, pada umumnya dengan beberapa indikator atau unsur yang mendukung. Indikator tersebut dapat diklasifikasikan sebagai berikut : (1) adanya hasrat dan keinginan berhasil, (2) adanya dorongan dan kebutuhan dalam belajar, (3) adanya harapan dan cita-cita masa depan, (4) adanya penghargaan dalam belajar, (5) adanya kegiatan yang menarik dalam belajar, (6) adanya lingkungan belajar yang kondusif, sehingga memungkinkan seorang siswa dapat belajar dengan baik.

Jadi motivasi adalah keseluruhan daya penggerak baik dari dalam diri maupun dari luar dengan menciptakan serangkaian usaha untuk menyediakan kondisi-kondisi tertentu yang menjamin kelangsungan dan memberikan arah pada kegiatan sehingga tujuan yang dikehendaki oleh subjek itu dapat tercapai.

Secara umum, motivasi dibedakan menjadi dua jenis yaitu motivasi intrinsik dan motivasi ekstrinsik. Menurut Sardiman (2007) motivasi intrinsik adalah motifmotif yang menjadi aktif dan berfungsi tidak perlu dirangsang dari luar karena dalam diri setiap individu sudah ada dorongan untuk melakukan sesuatu. Dengan kata lain, individu terdorong untuk bertingkah laku ke arah tujuan tertentu tanpa adanya faktor pendorong dari luar. Motivasi intrinsik tidak memerlukan rangsangan dari luar tetapi berasal dari diri siswa. Siswa yang termotivasi secara intrinsik dapat terlihat dari kegiatannya yang tekun dalam mengerjakan tugas-tugas belajar karena butuh dan ingin mencapai tujuan belajar yang sebenarnya.

Motivasi ekstrinsik berbeda dari motivasi intrinsik karena dalam motivasi ini keinginan siswa untuk belajar sangat dipengaruhi oleh adanya dorongan atau rangsangan dari luar. Dorongan dari luar tersebut dapat berupa pujian, celaan, hadiah, hukuman dan teguran dari guru.

Motivasi belajar sangat penting di dalam proses belajar dan pembelajaran karena motivasi belajar mendorong timbulnya tingkah laku dan mempengaruhi serta mengubah tingkah laku siswa.

Fungsi motivasi dalam belajar adalah mendorong manusia untuk melakukan suatu tugas atau perbuatan yang serasi guna mencapai tujuan yang dikehendaki dengan menyisihkan perbuatan-perbuatan yang tidak bermanfaat bagi tujuan tersebut.

\section{Hasil Belajar}

Menurut Sanjaya (2012:47) hasil belajar berkaitan dengan pencapaian dalam memperoleh kemampuan sesuai dengan tujuan khusus yang direncanakan. Tujuan 
khusus atau tujuan pembelajaran merupakan kemampuan yang harus dimiliki oleh anak didik setelah mereka mempelajari bahasan tertentu dalam bidang studi tertentu pula.

Sedangkan menurut Surya (2003:25), hasil pembelajaran ialah perubahan perilaku individu. Individu akan memperoleh perilaku yang baru, menetap, fungsional, positif, disadari, dan sebagainya.

Gagne dan Briggs (dalam Jurnal Teknodik, 2005:141) membagi hasil belajar menjadi 5 kategori yaitu (1) keterampilan intelektual (intellectual skills),(2) strategi kognitif (cognitive strategies), (3) informasi verbal (verbal information), (4) keterampilan motorik (motor skills), dan (5) sikap (attitudes).

Hasil belajar adalah suatu penilaian akhir dari proses dan pengenalan yang telah dilakukan berulang-ulang. Serta akan tersimpan dalam jangka waktu lama atau bahkan tidak akan hilang selama-lamanya karena hasil belajar turut serta dalam membentuk pribadi individu yang selalu ingin mencapai hasil yang lebih baik lagi sehingga akan merubah cara berpikir serta menghasilkan perilaku kerja yang lebih baik. Hasil belajar merupakan tingkat ketercapaian tujuan pembelajaran yang telah dirumuskan dalam bentuk kompetensi baik pada ranah kognitif, afektif maupun psikomotor.

\section{Multimedia Pembelajaran}

Menurut Robin dan Linda (dalam Darmawan, 2013:32) menyebutkan bahwa Multimedia sebagai alat yang dapat menciptakan presentasi yang dinamis dan interaktif yang mengombinasikan teks, grafik, animasi, audio dan video. Sedangkan pembelajaran diartikan sebagai proses penciptaan lingkungan yang memungkinkan terjadinya proses belajar.
Jadi pengertian dari Multimedia Pembelajaran adalah segala sesuatu yang digunakan untuk menyalurkan pesan (pengetahuan, keterampilan dan sikap) serta dapat merangsang pikiran, perasaan, perhatian dan kemauan belajar sehingga secara sengaja proses belajar terjadi, bertujuan dan terkendali (Warsita, 2008:154).

Bagi dosen membuat suasana kelas yang menarik dan tidak membosankan adalah idaman, caranya yaitu dengan membuat Multimedia pembelajaran interaktif salah satunya dengan menggunakan bantuan sofware I-Spring Presenter. Menurut Hernawan (2014:1) ISpring Presenter merupakan salah satu software atau tool yang dapat mengubah file presentasi menjadi bentuk flash serta dapat mengintegrasikan dalam software Microsoft Office Power Point.

Masih menurut Hernawan (2014:1) ada beberapa fitur I-Spring Presenter yaitu:

a. I-Spring Presenter bekerja sebagai add-ins Ms PowerPoint dan dapat menjadikan file Microsoft PowerPoint lebih menarik dan interaktif berbasis flash dan dapat dibuka pada setiap komputer.

b. I-Spring Presenter dapat menyisipkan berbagai bentuk media, sehingga media pembelajaran yang dihasilkan akan lebih menarik, diantaranya adalah dapat merekam dan sinkronisasi video presenter, menambahkan flash dan video youtube, mengimpor atau merekam audio, menambahkan informasi pembuat presentasi dan logo perusahaan, serta membuat navigasi dan desain yang unik.

c. Mudah didistribusikan dalam format flash, yang dapat digunakan dimanapun dan dioptimalkan untuk web. 
d. Membuat kuis dengan berbagai jenis pertanyaan/soal yaitu: True/False, Multiple Choice, Multiple response, Type In, Matching, Sequence, numeric, Fill in the Blank, Multiple Choice Text (pro).

\section{Pendidikan Kewarganegaraan di Perguruan Tinggi.}

Pendidikan Kewarganegaraan diberikan di Perguruan tinggi dengan tujuan agar mahasiswa memiliki wawasan akan kesadaran berbangsa dan bernegara untuk bela negara dan memiliki pola pikir, pola sikap dan prilaku sebagai pola tindak yang cinta tanah air berdasarkan Pancasila. Segala hal tersebut diperlukan agar Negara Kesatuan Republik Indonesia tetap utuh dan tidak terpecah belah.

Pendidikan Kewarganegaraan yang baik dan benar akan menghasilkan sikap dan mental mahasiswa yang cerdas dan memiliki rasa tanggung jawab yang penuh. Dengan dihasilkannya mahasiswa yang berkompetensi dalam pendidikan kewarganegaraan, maka akan meminimalisir masalah yang kompleks dalam permasalahan kesadaran dalam pendidikan bela negara dan bangsa Indonesia akan menjadi lebih aman dan tentram.

Karena demikian pentingnya pendidikan Kewarganegaraan dalam menumbuhkan karakter bangsa yang baik dan demi keutuhan Negara Kesatuan Republik Indonesia supaya tidak terpecah belah, maka keberhasilan pendidikan Kewarganegaraan harus diupayakan secara optimal.

Untuk mengantisifasi hal tersebut, penggunaan multimedia pembelajaran interaktif dengan I-Spring Presenter telah dilaksanakan dalam pembelajaran pendidikan Kewarganegaraan dan kelengkapan pembelajarannya pun telah selesai disiapkan.

\section{METODE PENELITIAN}

Penelitian ini menggunakan metode kuasi eksperimen, dalam pembelajaran ini jumlah keseluruhan mahasiswa adalah 118 orang yang terdiri atas tingkat $1 \mathrm{~A}$, tingkat 1B dan tingkat 1C. Dari tiga kelas yang ada dipilih satu kelas sebagai subjek sampel, yaitu kelas 1C sebagai kelompok eksperimen dengan jumlah mahasiswa sebanyak 38 orang dan kelas 1B sebagai kelas kontrol dengan jumlah mahasiswa 38 orang.

Adapun perlakuan kepada kelas eksperimen dan kelas kontrol diusahakan sama untuk metode penyampaian, metode pembelajaran, alat dan sumber pembelajarannya. Adapun yang membedakan hanya media pembelajarannya saja, dimana untuk kelas eksperimen menggunakan multimedia pembelajaran dengan I-Spring Presenter, sedangkan kelas kontrol menggunakan pembelajaran konvensional sampai tuntas (proses akhir pembelajaran atau tahapan evaluasi).

\section{HASIL DAN PEMBAHASAN}

Pada tahap pertama diberikan pretest motivasi terhadap kelas eksperimen yang berjumlah 38 mahasiswa. Kemudian diakhir pembelajaran diberikan lagi posttest motivasi. Adapun hasilnya dapat dilihat pada tabel dibawah ini. 
Tabel 1

\begin{tabular}{|c|c|c|c|c|c|c|}
\hline & \multicolumn{6}{|c|}{ Test Value $=0$} \\
\hline & & & & & \multicolumn{2}{|c|}{$95 \%$ Confidence Interval of the Difference } \\
\hline & $\mathrm{T}$ & $\mathrm{df}$ & Sig. (2-tailed) & Mean Difference & Lower & Upper \\
\hline $\begin{array}{l}\text { Motivasi } \\
\text { sebelum }\end{array}$ & 47.882 & 37 & .000 & 76.842 & 73.59 & 80.09 \\
\hline $\begin{array}{l}\text { Motivasi } \\
\text { sesudah }\end{array}$ & 37.173 & 37 & .000 & 133.684 & 126.40 & 140.97 \\
\hline
\end{tabular}

Berdasarkan tabel diatas dapat dilihat bahwa hasil pretest motivasi rata-rata sebesar 76,842, dan setelah diberikan pembelajaran dengan menggunakan multimedia interaktif dengan I-Spring Presenter, motivasinya meningkat rata-rata sebesar 133,684, hal ini menunjukkan adanya peningkatan motivasi mahasiswa dalam pembelajaran. Namun hal ini belum bisa dijadikan sebagai penarik kesimpulan bahwa pembelajaran dengan menggunakan multimedia interaktif ini bisa dikatakan efektif. Untuk mengetahui efektifitasnya harus dibuktikan dengan pengujian perbedaan kedua rata-rata tersebut. Adapun hasilnya bisa dilihat dalam tabel dibawah ini :

Tabel 2

Uji Perbedaan Motivasi Belajar

Ranks

\begin{tabular}{|ll|r|r|r|}
\hline & \multicolumn{1}{|c|}{$\mathrm{N}$} & Mean Rank & Sum of Ranks \\
\hline Motivasi sesudah - & Negative Ranks & $0^{\mathrm{a}}$ & .00 & .00 \\
Motivasi sebelum & Positive Ranks & $38^{\mathrm{b}}$ & 19.50 & 741.00 \\
& Ties & $0^{\mathrm{c}}$ & & \\
& Total & 38 & & \\
\hline
\end{tabular}

a. Motivasi sesudah < Motivasi sebelum

b. Motivasi sesudah > Motivasi sebelum

c. Motivasi sesudah = Motivasi sebelum

Test Statistics $^{b}$

\begin{tabular}{|l|r|}
\hline & Motivasi sesudah - Motivasi sebelum \\
\hline$Z$ & $-5.384^{\mathrm{a}}$ \\
Asymp. Sig. (2-tailed) & .000 \\
\hline
\end{tabular}

a. Based on negative ranks.

b. Wilcoxon Signed Ranks Test 
Dari tabel diatas, seluruh Mahasiswa mengalami kenaikan motivasi belajar. Pada tabel bagian kedua, diperoleh nilai $\mathrm{z}$ sebesar -5,384 dengan Asym.Sig (2-tailed) lebih kecil dari $\alpha$, maka Ha diterima dan Ho ditolak. Karena pada pengujian ini nilai Asym.Sig (2-tailed) $=0,000$ lebih kecil dari $\alpha=0,05$, maka Ha diterima, sehingga dapat disimpulkan bahwa : "Terdapat perbedaan peningkatan motivasi belajar antara sebelum menggunakan multimedia pembelajaran dan setelah menggunakan multimedia pembelajaran .

Pada tahap berikutnya, peneliti melaksanakan pretest soal kewarganegaraan, setelah itu diadakan proses pembelajaran Pendidikan Kewarganegaraan. Dimana untuk kelas eksperimen, proses pembelajaran menggunakan multimedia pembelajaran interaktif dengan I Spring Presenter, sedangkan untuk kelas kontrol proses pembelajaran dilaksanakan dengan cara konvensional (ceramah biasa). Setelah dilaksanakan proses pembelajaran, kemudian diadakan posttest baik di kelas eksperimen maupun di kelas kontrol. Adapun hasil pretest dan posttest kelas eksperimen dapat dilihat pada tabel dibawah ini.

Tabel 3

Rekapitulasi Peningkatan Hasil Belajar Kelas Eksperimen

\begin{tabular}{|l|r|r|}
\hline & Hasil pretest kelas eksperimen & Hasil posttest kelas eksperimen \\
\hline N $\quad$ Valid & 38 & 38 \\
\multicolumn{1}{|c|}{ Missing } & 0 & 0 \\
Mean & 48.68 & 82.37 \\
Median & 50.00 & 80.00 \\
Std. Deviation & 10.180 & 7.141 \\
Variance & 103.627 & 50.996 \\
Kurtosis & 1.376 & .629 \\
Std. Error of Kurtosis & .750 & .750 \\
Range & 50 & 30 \\
Minimum & 20 & 70 \\
Maximum & 70 & 100 \\
\hline
\end{tabular}

Dari tabel diatas dapat terlihat mahasiswa yang mendapat pembelajaran dengan menggunakan multimedia pembelajaran mengalami peningkatan dari rata-rata sebelumnya 48,68 menjadi 82,37.

Selanjutnya untuk mengetahui besarnya pengaruh motivasi belajar dengan menggunakan multimedia pembelajaran terhadap hasil belajar, terlebih dahulu melakukan uji sebaran normalitas data dari kedua data tersebut. Dari hasil perhitungan uji normalitas didapatkan sebaran data seperti yang disajikan pada tabel berikut ini : 


\section{Tabel 4}

\section{Uji Sebaran Normalitas Data Hasil Belajar dan Motivasi Belajar}

Tests of Normality

\begin{tabular}{|l|r|r|r|r|r|r|}
\hline & \multicolumn{3}{|c|}{ Kolmogorov-Smirnov $^{\text {a }}$} & \multicolumn{3}{c|}{ Shapiro-Wilk } \\
\cline { 2 - 7 } & Statistic & Df & \multicolumn{1}{c|}{ Sig. } & Statistic & Df & \multicolumn{1}{c|}{ Sig. } \\
\hline Motivasi & .138 & 38 & .067 & .951 & 38 & .099 \\
Prestasi & .239 & 38 & .000 & .913 & 38 & .004 \\
\hline
\end{tabular}

a. Lilliefors Significance Correction

Kriteria sebaran berdistribusi normal jika nilai Sig lebih besar dari taraf signifikansi yang digunakan $(\alpha)$. Dalam penelitian ini $\alpha$ yang digunakan sebesar 0,05, sebaran data hasil belajar dengan menggunakan multimedia pembelajaran dan motivasi belajar Mahasiswa berturutturut mempunyai nilai $\mathrm{Sig}=0,099$ dan
0,004, karena salah satu datanya lebih kecil dari $\alpha$ sehingga sebaran data salah satunya berdistribusi tidak normal.

Untuk pengujian selanjutnya karena sebaran data salah satunya berdistribusi tidak normal, maka digunakan uji statistika non parametric dalam hal ini digunakan korelasi Rank-Spearman.

Tabel 5

Uji Koefisien Korelasi

Correlations

\begin{tabular}{|lll|r|r|}
\hline & & $\begin{array}{c}\text { Posttest } \\
\text { eksperimen }\end{array}$ & $\begin{array}{c}\text { Motivasi } \\
\text { Multimedia }\end{array}$ \\
\hline $\begin{array}{l}\text { Spearman's } \\
\text { rho }\end{array}$ & Posttest & Correlation Coefficient & 1.000 & .193 \\
& Eksperimen & Sig. (2-tailed) &. & .245 \\
& & $\mathrm{~N}$ & 38 & 38 \\
\cline { 2 - 5 } & Motivasi & Correlation Coefficient & .193 & 1.000 \\
& Multimedia & Sig. (2-tailed) & .245 & 38 \\
& & $\mathrm{~N}$ & 38 &. \\
\hline
\end{tabular}

Kriteria pengaruh dikatakan signifikan jika nilai Sig (2 tailed) lebih kecil dari $\alpha$ yang digunakan sebesar 0,05, sedangkan nilai Sig ( 2 tailed) sebesar 0,0245 maka Ho 
ditolak dan Ha diterima, sehingga dapat disimpulkan bahwa terdapat pengaruh yang signifikan antara motivasi belajar dengan menggunakan multimedia pembelajaran terhadap hasil belajar.

\section{E. SIMPULAN DAN REKOMENDASI}

Hasil penelaahan memberikan gambaran sebagai berikut, pertama penggunaan multimedia pembelajaran interaktif dengan I-Spring Presenter dapat meningkatkan motivasi mahasiswa khususnya pada pembelajaran Pendidikan Kewarganegaraan. Hal ini didasarkan pada meningkatnya skor motivasi belajar mahasiswa setelah diberikan pembelajaran dengan menggunakan multimedia pembelajaran interaktif dengan I-Spring Presenter. Kedua penggunaan multimedia pembelajaran interaktif dengan I-Spring Presenter dapat meningkatkan hasil belajar mahasiswa. Dalam hal ini hasil belajar yang menggunakan multimedia pembelajaran interaktif mengalami peningkatan secara signifikan.

Sehingga dari hasil tersebut diharapkan pada mata kuliah lain dapat menggunakan multimedia pembelajaran interaktif dengan I-Spring Presenter sebagai salah satu langkah untuk meningkatkan motivasi dan hasil belajar mahasiswa.

\section{F. REFERENSI}

Darmawan, Deni (2013), Pendidikan
Teknologi Informasi dan

Komunikasi, Teori dan Aplikasi,

Bandung: PT Remaja Rosdakarya

Hernawan, Hudiana, (2014), Modul

Kuliah Pembuatan Multimedia

dengan bantuan Software I-Spring

Presenter

Sanjaya, Wina (2012), Media Komunikasi

Pembelajaran, Jakarta : Kencana

Prenada Media Group.

Sardiman, A.M, (2007), Interaksi dan Motivasi Belajar Mengajar, Jakarta :

PT Raja Grafindo Persada

Sumarsono,dkk, (2008), Pendidikan Kewarganegaraan, Jakarta : PT Gramedia Pustaka Utama

Surya, Mohamad, H (2003), Psikologi Pembelajaran dan Pengajaran, Bandung : Yayasan Bhakti Winaya.

Uno, B.Hamzah (2012), Teori Motivasi dan Pengukurannya, Analisis di bidang Pendidikan, Jakarta : Bumi Aksara

Warsita, Bambang (2008), Teknologi Pembelajaran, Landasan dan aplikasinya, Jakarta : Rineka Cipta.

Undang-Undang Republik Indonesia No. 20 Tahun 2003 tentang Sistem Pendidikan Nasional, (2010), Bandung : Nuansa Aulia

Jurnal Teknodik (2005), Pustekom Departemen Pendidikan Nasional. 